\title{
Comparison Between the Reality of Higher Education in the Kurdistan Region of Iraq Before and After the Fall of the Regime in Iraq in 2003
}

\author{
Ezzadin. N. M.Amin Baban \\ Rezan 0. Rashid \\ Sulaimani University, Faculty of Science (IRAQ) \\ Zhala A. Al \\ Directories of social care / Erbil
}

\begin{abstract}
In this study, a comparison between the realities of higher education in the three largest universities in the Kurdistan Region of Iraq has been done before the fall of the Iraqi regime in 2003 and beyond. The statistical results of analyzed of more than 2000 sample data showed tangible and clear changes of the higher education reality toward the better of about $70 \%$ after the fall of the Iraqi regime in 2003. These changes are related to the openness of these universities toward the foreign universities of the world especially the European universities. Many professors and students of these universities contacted to the foreign universities to conduct joint research and take advantage of new experiences of professors of these foreign universities and using the new technology in teaching enhanced learning and scientific research, in addition to the using of new references such as journals and books. As well as the improved economic situation in the Region from a low level to the moderate level improved higher education by $20 \%$, especially after the entry of many investment companies to the region and improved infrastructure and accessibility delegations to the region through the newly built airports.
\end{abstract}

Keywords: Higher education, university, Iraqi Kurdistan Region, teaching.

\section{Introduction}

The Iraqi Kurdistan Region before year 2003 was under two embargos; one was of United Nations and the other of Iraqi regime. In that time all the materials and things can not allowed shipping, export or reached to the Kurdistan region in official ways. No references such as books, Journals, disks, CD, computer and its accessories, ...etc allowed to enter the area. For example: if a student or any person who want to enter the Kurdistan region and holding a book or Journal, at Turkish or Syrian check points they terrible him and don't allowed to took it and sometime he goes to prison because that?!. In addition, the economic condition of the government and population was very weak. So the higher education was not easy done and then many students leave the study or not ready to registered Even though some supervised professors greatly facilitate for them. To explain how these two embargoes constraints and impact on higher education studies and how much releasing of these two embargoes contribute to progress the study.

\section{Methodology}

For study this case we designed a form consist of 26 different questions related to the most modern techniques and tools used in teaching and researching, some of these tools were not available before year 2003 but most of them available after that time (now).

The form includes five answers which are; 1- More useful, 2- Medium useful, 3- Little useful, 4- Zero (nothing) using and 5unavailable this tools (Appendix-A).

About 237 of this form were distributed on postgraduate and graduates (teachers) of three universities in the region which are Salahaddin - Erbil, Sulaimani and Kirkuk universities. 
After collection the fill forms and sorting the data, several contour map, Pie and histograms were built to study the higher education state in both cases (before year 2003 and after the fall of Baath regime in 2003).

Results and Discussion

The contour map of the five answers of all 26 question was drawn (Fig. 1).

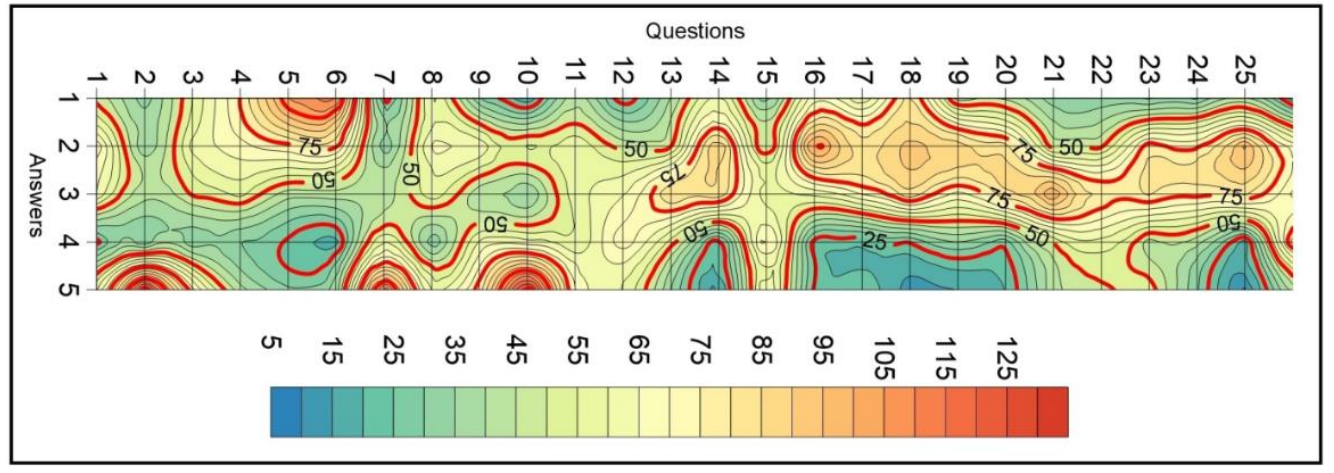

Fig. (1) show the contour map of the five answers of all of 26 questions.

The map shows that the more answers concentrated on answers;

with 2- "Medium" useful of questions 4-6, 14, 16-20, 23 and 25.

with 3- "Little" useful of questions 1 and 3

with 5- "Unavailable" of questions 2, 7 and 10

with 1- "More" useful of questions 4-6 and 18.

with 4- zero "un-useful" of question 7

It means that the available of book, computer and internet uses after year 2003 helps the higher education student in their study. Also Available of different specialize of supervisors (local), Social relations between teachers and students, different references, Available of libraries and modern scientific references, Availability and uses of foreign references such as English, and Appropriate classrooms contribute the Improvement of the study.

\section{Histogram of Number of each answers of each all questions}

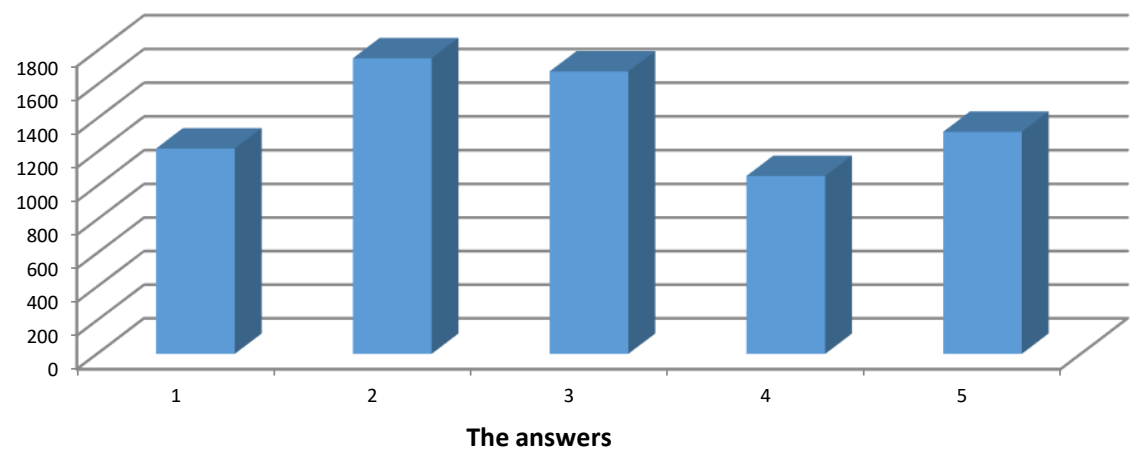

Fig (2) Histogram of Number of each answers of each all questions 
While the availability of transportation means (aircraft and modern cars ...), Ease of travel and movement between provinces contribute in improvement of the study but not as the above answers.

In general, most of the answers concentrated on medium more than other answers Fig (2). Also several tens of answers focused on unavailable tools especially on point (Question 2) which is "travel outside the country", video conference, elearning and multimedia. Most of these answer of students, which were graduated before 2003, (Fig. 3).

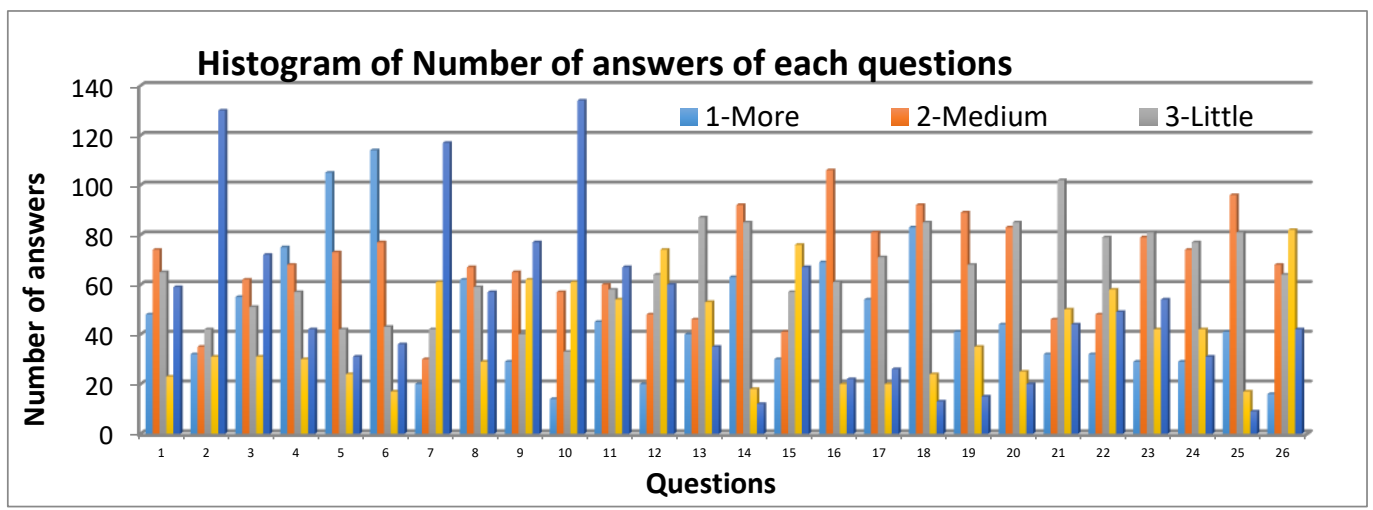

Fig. (3) Percentage of each answers of the question.
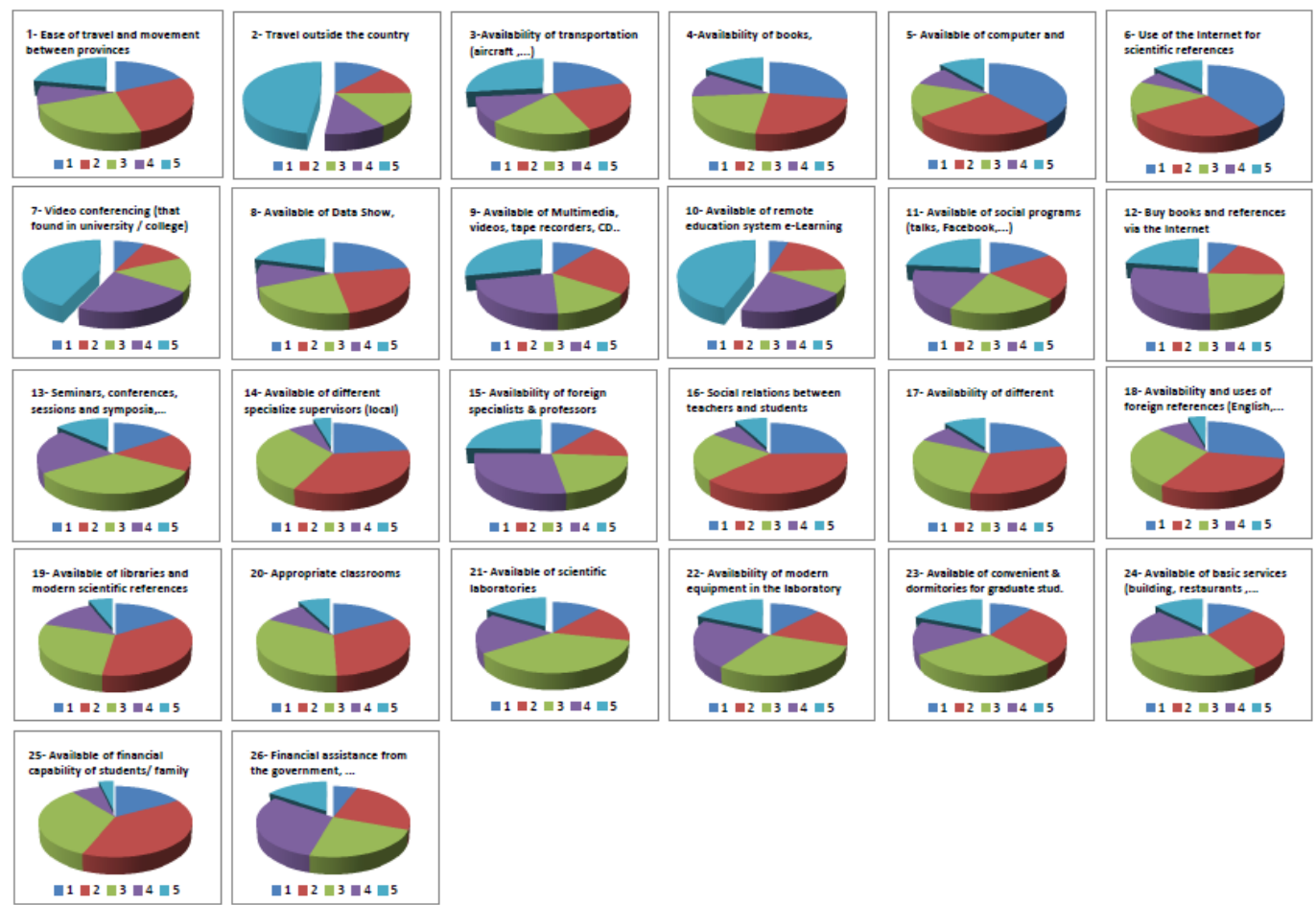

Fig.(4) Histograms for all 26 questions and its distribution of the five answers of (1- More, 2- Medium, 3- Little, 4- Zero and 5- Unavailable for each questions. 

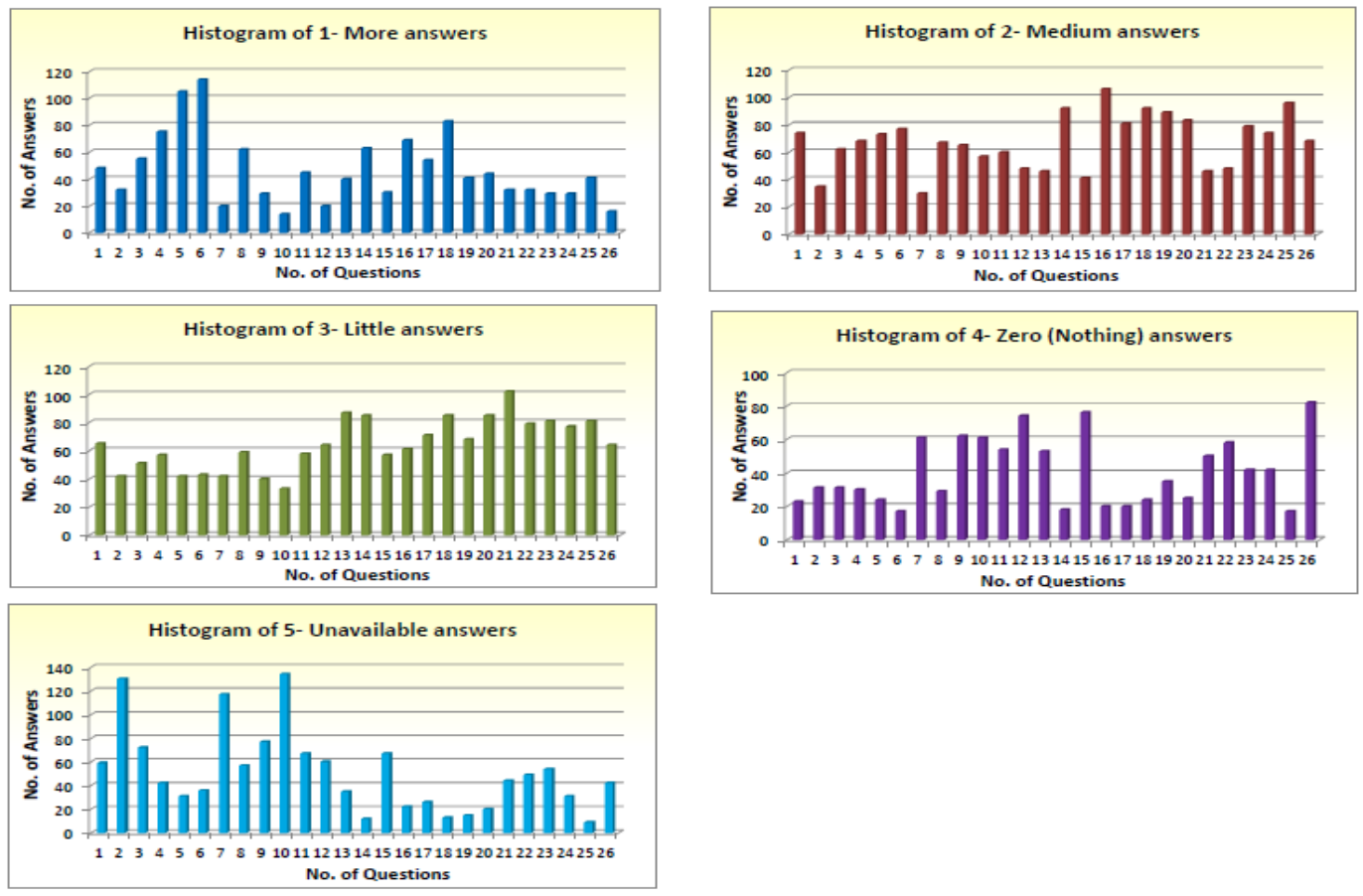

Fig. (5) Histograms for sum of the five answers (1-More, 2- Medium, 3- Little, 4-Zero and 5- Unavailable) for each question of all 26 questions and its distributions

Figs (4 and 5) show result more clearly and the more useful tools are journal, books, e- books, e-journal, computer and its accessories, internet uses, different specialize superviors of local, social relation between the teachers and students, availability of foreign references and economical capability of the students and her/his families.

We can say in general that all to tools and facilities help the higher education to progress more steps (Fig. 5 histogram of medium answers).

Most of the answers refer that they not benefit from governorate or other non-governorate financial supports (Question 26; Financial assistance from the government or non-government organization). We surprised from this result because we know that all the stages of the educations are free in Kurdistan region and Iraq and this is a big support from the government to all branches of the studies from primary schools to postgraduate too. May be they refer to did not got a special salary which is available now for student for both studying inside or outside the country. 


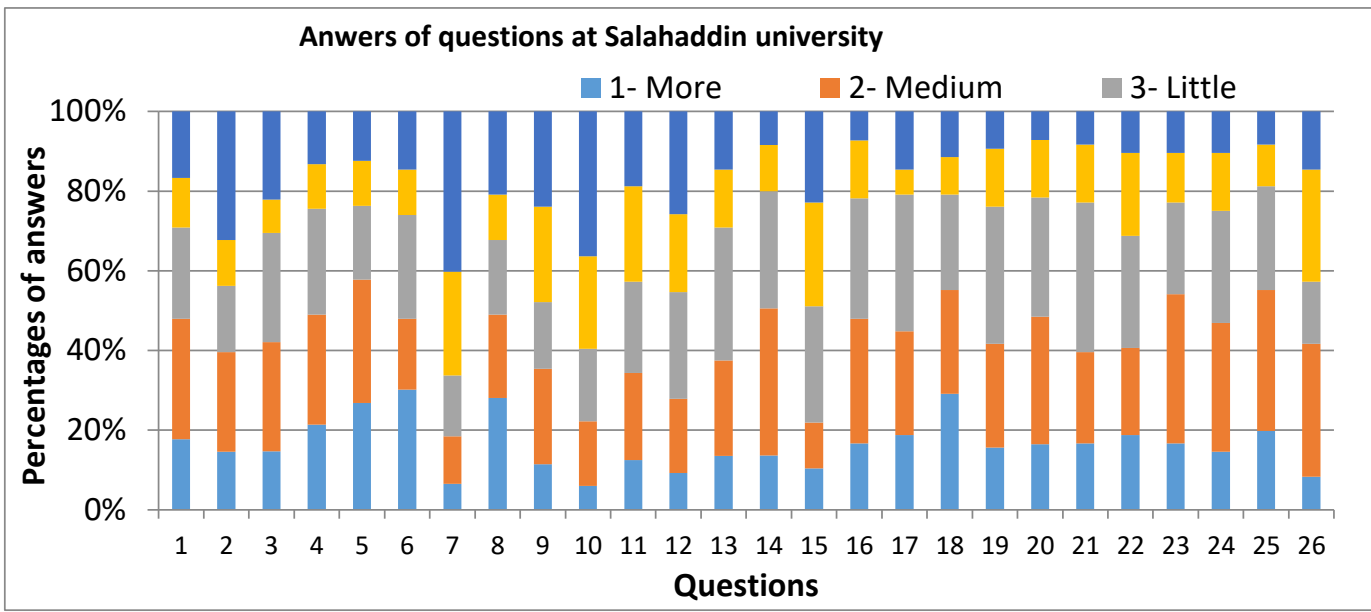

Fig. (6) Histograms for percentage of each answer of all questions in Salahaddin University- Erbil.

The $100 \%$ stacked histogram of Salahaddin University answers (Fig. 6 and table 2) indicate that the three answers 1-More, 2- Medium and 3-Little are the more answers. In other words, it means that they benefit from availability and uses of the tools and references.

Only the video conferences and e-learning are unavailable and they not benefit from it.

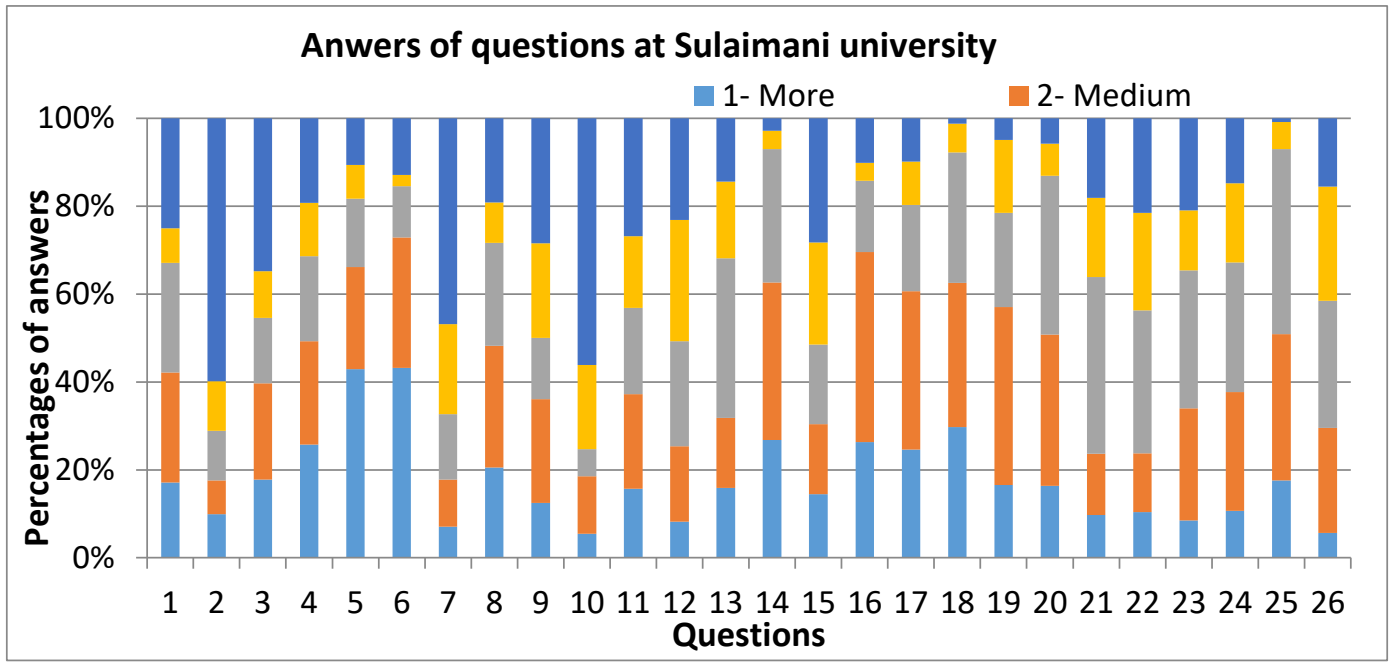

Fig. (7) Histograms for percentage of each answer of all questions in Sulaimani University.

Also, the $100 \%$ stacked histogram of Sulaimani university answers (Fig. 7 and table 3) indicate that the three answers 1More, 2- Medium and 3-Little are the more answers. Also, it means that they benefit from availability and uses of the tools and references.

The Transportation such as aircrafts, modern transportation machines, video conferences and e-learning are unavailable and they not benefit from it. 


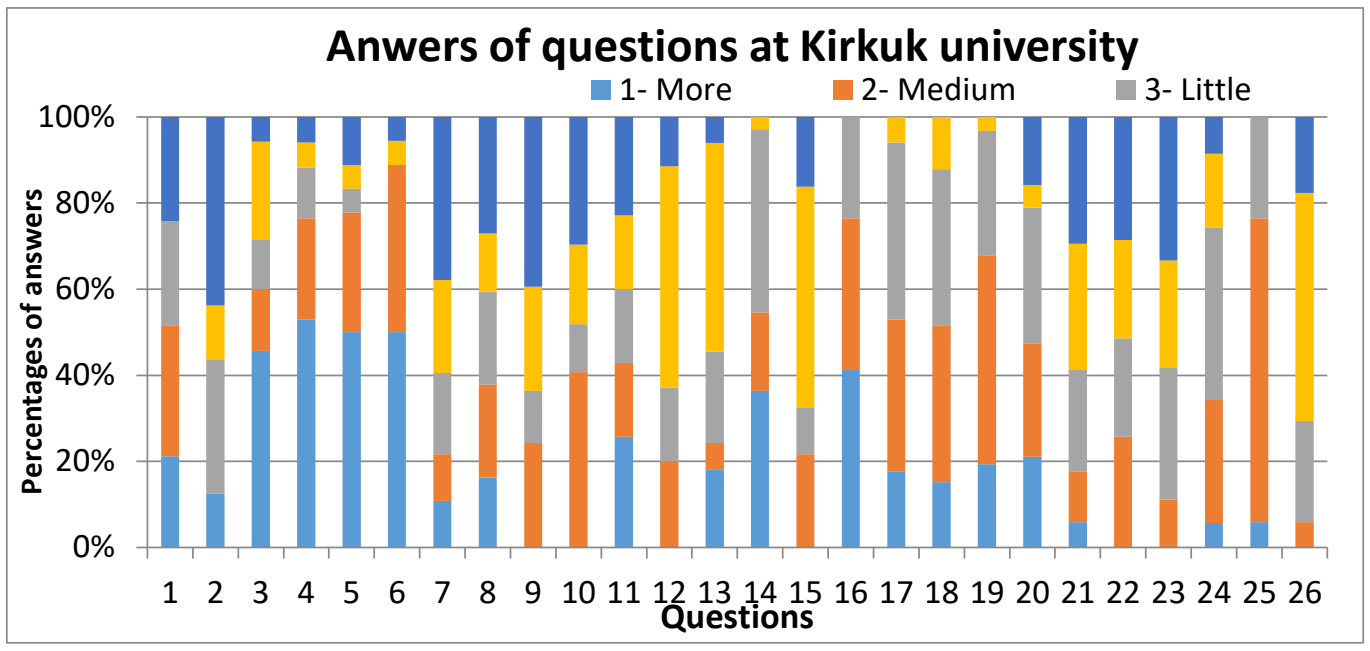

Fig. (8) Histograms for percentage of each answer of all questions in Kirkuk University.

while, the $100 \%$ stacked histogram of Kirkuk university answers (Fig. 8 and table 4) indicate that the three answers 1 More, 2- Medium and 3-Little are not uniform answers. But also, they benefit from availability and uses of the tools and references especially answers of question 3-6,11, 14 and 16 .

The Transportation such as aircrafts, modern transportation machines, video conferences, multimedia, e-learning and convenient and dormitories for graduate students are unavailable and they not benefit from it.

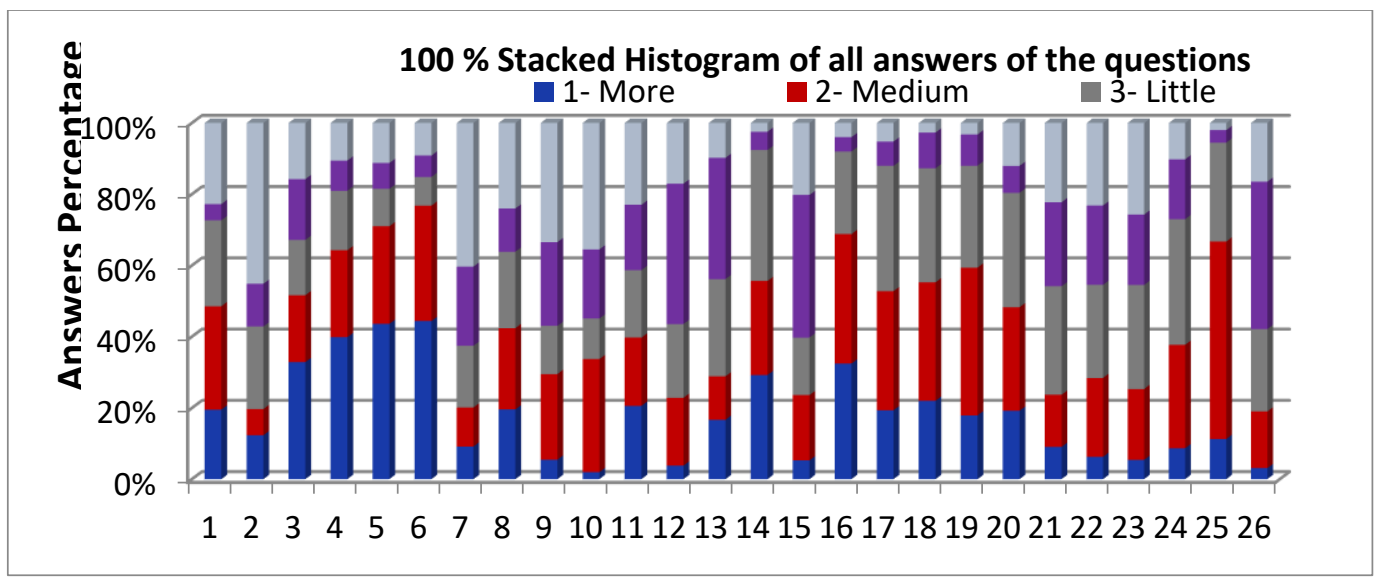

Fig. (9) Histograms for percentage of each answer of all questions of the three Universities.

Finally, the Fig. 9 and table (5) which represents the data and the 100\% stacked histogram of summation of all the data of the three universities and show that all them benefit from availability of references, computers, internet resources, available of different local supervisors and social relations between the teachers and student. On the contrary, they not benefit from multimedia, remote learning, video conference, foreign supervisors, modern equipment and laboratories and financial supporting because they were unavailable.

That is means the changing or fall of the Iraqi regime after 2003 contribute to progress the study because the country is opened and the embargos were released and the economic situation got better and all the modern materials, devices and tools enters the country as well as the borders were becomes more flexible. 


\section{Conclusions:}

We can conclude the results in the following points:

In general, all the higher education student benefit from the fallen and changing of the regime in 2003 and the country is opened and the effects of the embargos were released and the borders are become more flexible.

They benefit from availability of electronic resources, using of computer and its accessories, internet uses and transportation.

May be the unavailable of video conference, multimedia tools, modern laboratories and convenient and dormitories for graduate students are impediment the study.

\section{Appendix - A. Designed Form}

Sex : University:

Starting study Date:

Ending study Date :

\begin{tabular}{|c|c|c|c|c|c|c|}
\hline $\begin{array}{l}\mathbf{N} \\
0\end{array}$ & Question & $\begin{array}{l}\text { 1- } \\
\text { More }\end{array}$ & $\begin{array}{l}\text { 2- Me } \\
\text { dium }\end{array}$ & $\begin{array}{l}\text { 3- } \\
\text { Little }\end{array}$ & $\begin{array}{l}\text { 4- } \\
\text { Zero }\end{array}$ & $\begin{array}{l}\text { 5- Not } \\
\text { availabl } \\
\text { e }\end{array}$ \\
\hline 1 & Ease of travel and movement between provinces & & & & & \\
\hline 2 & Travel outside the country & & & & & \\
\hline 3 & Availability of transportation tools (aircraft \& modern cars,...) & & & & & \\
\hline 4 & Availability of books, magazines and electronic references; e-book, & & & & & \\
\hline 5 & $\begin{array}{l}\text { Âvinunal } \\
\text { Available of computer and it's accessories such as printers, storage }\end{array}$ & & & & & \\
\hline 6 & Use of the Internet for scientific references & & & & & \\
\hline 7 & Video conferencing (that found in university or college) & & & & & \\
\hline 8 & Available of Data Show, electronic blackboards, ... & & & & & \\
\hline 9 & Available of Multimedia, videos, tape recorders and CD.. & & & & & \\
\hline 10 & Available of remote education system; e-Learning, ... & & & & & \\
\hline 11 & Available of social programs (talks, Facebook, chatting) & & & & & \\
\hline 12 & Buy books and references via the Internet & & & & & \\
\hline 13 & Seminars, conferences, sessions and symposia, ... & & & & & \\
\hline 14 & Available of different specialize of supervisors (local) & & & & & \\
\hline 15 & Availability of foreign specialists \& professors & & & & & \\
\hline 16 & Social relations between teachers and students & & & & & \\
\hline 17 & Availability of different references & & & & & \\
\hline 18 & Availability and uses of foreign references such as English,... & & & & & \\
\hline 19 & Available of libraries and modern scientific references & & & & & \\
\hline 20 & Appropriate classrooms & & & & & \\
\hline 21 & Available of scientific laboratories & & & & & \\
\hline 22 & Availability of modern equipment in the laboratory & & & & & \\
\hline 23 & Available of convenient and dormitories for graduate students & & & & & \\
\hline 24 & Available of basic services such as building, restaurants of the & & & & & \\
\hline 25 & Avvailable of financial capabilities of students \& his/her families & & & & & \\
\hline 26 & Financial assistance from the government or non-governmental & & & & & \\
\hline
\end{tabular}


Appendix - 2. Table (1) Sorted answers of the Higher education graduates of the 3 universities.

\begin{tabular}{|c|c|c|c|c|c|c|c|c|c|c|c|c|c|c|c|c|c|c|c|c|c|}
\hline \multirow{2}{*}{ No } & \multicolumn{4}{|c|}{ 1-More } & \multicolumn{4}{|c|}{ 2-Medium } & \multicolumn{4}{|c|}{ 3-Little } & \multicolumn{4}{|c|}{ 4-Zero (nothing) } & \multicolumn{4}{|c|}{ 5- Not avialable } & \multirow[t]{2}{*}{ Total } \\
\hline & H & s & K & Sum & H & $s$ & $\mathrm{~K}$ & Sum & H & s & K & Sum & H & $s$ & K & Sum & $\mathrm{H}$ & s & K & Sum & \\
\hline 1 & 17 & 24 & 7 & 48 & 29 & 35 & 10 & 74 & 22 & 35 & 8 & 65 & 12 & 11 & 0 & 23 & 16 & 35 & 8 & 59 & 269 \\
\hline 2 & 14 & 14 & 4 & 32 & 24 & 11 & 0 & 35 & 16 & 16 & 10 & 42 & 11 & 16 & 4 & 31 & 31 & 85 & 14 & 130 & 270 \\
\hline 3 & 14 & 25 & 16 & 55 & 26 & 31 & 5 & 62 & 26 & 21 & 4 & 51 & 8 & 15 & 8 & 31 & 21 & 49 & 2 & 72 & 271 \\
\hline 4 & 21 & 36 & 18 & 75 & 27 & 33 & 8 & 68 & 26 & 27 & 4 & 57 & 11 & 17 & 2 & 30 & 13 & 27 & 2 & 42 & 272 \\
\hline 5 & 26 & 61 & 18 & 105 & 30 & 33 & 10 & 73 & 18 & 22 & 2 & 42 & 11 & 11 & 2 & 24 & 12 & 15 & 4 & 31 & 275 \\
\hline 6 & 29 & 67 & 18 & 114 & 17 & 46 & 14 & 77 & 25 & 18 & 0 & 43 & 11 & 4 & 2 & 17 & 14 & 20 & 2 & 36 & 287 \\
\hline 7 & 6 & 10 & 4 & 20 & 11 & 15 & 4 & 30 & 14 & 21 & 7 & 42 & 24 & 29 & 8 & 61 & 37 & 66 & 14 & 117 & 270 \\
\hline 8 & 27 & 29 & 6 & 62 & 20 & 39 & 8 & 67 & 18 & 33 & 8 & 59 & 11 & 13 & 5 & 29 & 20 & 27 & 10 & 57 & 274 \\
\hline 9 & 11 & 18 & 0 & 29 & 23 & 34 & 8 & 65 & 16 & 20 & 4 & 40 & 23 & 31 & 8 & 62 & 23 & 41 & 13 & 77 & 273 \\
\hline 10 & 6 & 8 & 0 & 14 & 16 & 19 & 22 & 57 & 18 & 9 & 6 & 33 & 23 & 28 & 10 & 61 & 36 & 82 & 16 & 134 & 299 \\
\hline 11 & 12 & 24 & 9 & 45 & 21 & 33 & 6 & 60 & 22 & 30 & 6 & 58 & 23 & 25 & 6 & 54 & 18 & 41 & 8 & 67 & 284 \\
\hline 12 & 9 & 11 & 0 & 20 & 18 & 23 & 7 & 48 & 26 & 32 & 6 & 64 & 19 & 37 & 18 & 74 & 25 & 31 & 4 & 60 & 266 \\
\hline 13 & 13 & 21 & 6 & 40 & 23 & 21 & 2 & 46 & 32 & 48 & 7 & 87 & 14 & 23 & 16 & 53 & 14 & 19 & 2 & 35 & 261 \\
\hline 14 & 13 & 38 & 12 & 63 & 35 & 51 & 6 & 92 & 28 & 43 & 14 & 85 & 11 & 6 & 1 & 18 & 8 & 4 & 0 & 12 & 270 \\
\hline 15 & 10 & 20 & 0 & 30 & 11 & 22 & 8 & 41 & 28 & 25 & 4 & 57 & 25 & 32 & 19 & 76 & 22 & 39 & 6 & 67 & 271 \\
\hline 16 & 16 & 39 & 14 & 69 & 30 & 64 & 12 & 106 & 29 & 24 & 8 & 61 & 14 & 6 & 0 & 20 & 7 & 15 & 0 & 22 & 278 \\
\hline 17 & 18 & 30 & 6 & 54 & 25 & 44 & 12 & 81 & 33 & 24 & 14 & 71 & 6 & 12 & 2 & 20 & 14 & 12 & 0 & 26 & 252 \\
\hline 18 & 28 & 50 & 5 & 83 & 25 & 55 & 12 & 92 & 23 & 50 & 12 & 85 & 9 & 11 & 4 & 24 & 11 & 2 & 0 & 13 & 297 \\
\hline 19 & 15 & 20 & 6 & 41 & 25 & 49 & 15 & 89 & 33 & 26 & 9 & 68 & 14 & 20 & 1 & 35 & 9 & 6 & 0 & 15 & 248 \\
\hline 20 & 16 & 20 & 8 & 44 & 31 & 42 & 10 & 83 & 29 & 44 & 12 & 85 & 14 & 9 & 2 & 25 & 7 & 7 & 6 & 20 & 257 \\
\hline 21 & 16 & 14 & 2 & 32 & 22 & 20 & 4 & 46 & 36 & 58 & 8 & 102 & 14 & 26 & 10 & 50 & 8 & 26 & 10 & 44 & 274 \\
\hline 22 & 18 & 14 & 0 & 32 & 21 & 18 & 9 & 48 & 27 & 44 & 8 & 79 & 20 & 30 & 8 & 58 & 10 & 29 & 10 & 49 & 266 \\
\hline 23 & 16 & 13 & 0 & 29 & 36 & 39 & 4 & 79 & 22 & 48 & 11 & 81 & 12 & 21 & 9 & 42 & 10 & 32 & 12 & 54 & 285 \\
\hline 24 & 14 & 13 & 2 & 29 & 31 & 33 & 10 & 74 & 27 & 36 & 14 & 77 & 14 & 22 & 6 & 42 & 10 & 18 & 3 & 31 & 253 \\
\hline 25 & 19 & 20 & 2 & 41 & 34 & 38 & 24 & 96 & 25 & 48 & 8 & 81 & 10 & 7 & 0 & 17 & 8 & 1 & 0 & 9 & 244 \\
\hline 26 & 8 & 8 & 0 & 16 & 32 & 34 & 2 & 68 & 15 & 41 & 8 & 64 & 27 & 37 & 18 & 82 & 14 & 22 & 6 & 42 & 272 \\
\hline Total & 412 & 647 & 163 & 1222 & 643 & 882 & 232 & 1757 & 634 & 843 & 202 & 1679 & 391 & 499 & 169 & 1059 & 418 & 751 & 152 & 1321 & 7038 \\
\hline
\end{tabular}

Table (2) Sorting of answers of the questions of Salahaddin university Higher Educ.

\begin{tabular}{|l|l|l|l|l|l|l|l|l|l|l|}
\hline \multirow{2}{*}{ No } & \multicolumn{9}{|c|}{ Salahaddin university - Erbil } \\
\cline { 2 - 12 } & 1- More & \multicolumn{2}{|l|}{ 2-Medium } & \multicolumn{2}{l|}{ 3- Little } & \multicolumn{2}{l|}{ 4-Zero/ nothing } & \multicolumn{2}{|c|}{ 5- Not avia-lable } \\
\cline { 2 - 12 } & No & $\%$ & No & $\%$ & No & $\%$ & No & $\%$ & No & $\%$ \\
\hline 1 & 17 & 0.18 & 29 & 0.30 & 22 & 0.23 & 12 & 0.13 & 16 & 0.17 \\
\hline 2 & 14 & 0.15 & 24 & 0.25 & 16 & 0.17 & 11 & 0.11 & 31 & 0.32 \\
\hline 3 & 14 & 0.15 & 26 & 0.27 & 26 & 0.27 & 8 & 0.08 & 21 & 0.22 \\
\hline 4 & 21 & 0.22 & 27 & 0.28 & 26 & 0.27 & 11 & 0.11 & 13 & 0.14 \\
\hline 5 & 26 & 0.27 & 30 & 0.31 & 18 & 0.19 & 11 & 0.11 & 12 & 0.13 \\
\hline 6 & 29 & 0.30 & 17 & 0.18 & 25 & 0.26 & 11 & 0.11 & 14 & 0.15 \\
\hline 7 & 6 & 0.06 & 11 & 0.11 & 14 & 0.15 & 24 & 0.25 & 37 & 0.39 \\
\hline
\end{tabular}




\begin{tabular}{|l|l|l|l|l|l|l|l|l|l|l|}
8 & 27 & 0.28 & 20 & 0.21 & 18 & 0.19 & 11 & 0.11 & 20 & 0.21 \\
\hline 9 & 11 & 0.11 & 23 & 0.24 & 16 & 0.17 & 23 & 0.24 & 23 & 0.24 \\
\hline 10 & 6 & 0.06 & 16 & 0.17 & 18 & 0.19 & 23 & 0.24 & 36 & 0.38 \\
\hline 11 & 12 & 0.13 & 21 & 0.22 & 22 & 0.23 & 23 & 0.24 & 18 & 0.19 \\
\hline 12 & 9 & 0.09 & 18 & 0.19 & 26 & 0.27 & 19 & 0.20 & 25 & 0.26 \\
\hline 13 & 13 & 0.14 & 23 & 0.24 & 32 & 0.33 & 14 & 0.15 & 14 & 0.15 \\
\hline 14 & 13 & 0.14 & 35 & 0.36 & 28 & 0.29 & 11 & 0.11 & 8 & 0.08 \\
\hline 15 & 10 & 0.10 & 11 & 0.11 & 28 & 0.29 & 25 & 0.26 & 22 & 0.23 \\
\hline 16 & 16 & 0.17 & 30 & 0.31 & 29 & 0.30 & 14 & 0.15 & 7 & 0.07 \\
\hline 17 & 18 & 0.19 & 25 & 0.26 & 33 & 0.34 & 6 & 0.06 & 14 & 0.15 \\
\hline 18 & 28 & 0.29 & 25 & 0.26 & 23 & 0.24 & 9 & 0.09 & 11 & 0.11 \\
\hline 19 & 15 & 0.16 & 25 & 0.26 & 33 & 0.34 & 14 & 0.15 & 9 & 0.09 \\
\hline 20 & 16 & 0.17 & 31 & 0.32 & 29 & 0.30 & 14 & 0.15 & 7 & 0.07 \\
\hline 21 & 16 & 0.17 & 22 & 0.23 & 36 & 0.38 & 14 & 0.15 & 8 & 0.08 \\
\hline 22 & 18 & 0.19 & 21 & 0.22 & 27 & 0.28 & 20 & 0.21 & 10 & 0.10 \\
\hline 23 & 16 & 0.17 & 36 & 0.38 & 22 & 0.23 & 12 & 0.13 & 10 & 0.10 \\
\hline 24 & 14 & 0.15 & 31 & 0.32 & 27 & 0.28 & 14 & 0.15 & 10 & 0.10 \\
\hline 25 & 19 & 0.20 & 34 & 0.35 & 25 & 0.26 & 10 & 0.10 & 8 & 0.08 \\
\hline 26 & 8 & 0.08 & 32 & 0.33 & 15 & 0.16 & 27 & 0.28 & 14 & 0.15 \\
\hline
\end{tabular}

Table (3) Sorting of answers of the questions of Sulaimani university Higher Educ.

\begin{tabular}{|l|l|l|l|l|l|l|l|l|l|l|}
\hline \multirow{2}{*}{ No } & \multicolumn{9}{|c|}{ Sulaimani university } \\
\cline { 2 - 11 } & 1- More & \multicolumn{2}{|c|}{ 2-Medium } & \multicolumn{2}{l|}{ 3- Little } & \multicolumn{2}{l|}{ 4-Zero/ nothing } & \multicolumn{2}{l|}{ - Not avia-lable } \\
\cline { 2 - 11 } & No & $\%$ & No & $\%$ & No & $\%$ & No & $\%$ & No & $\%$ \\
\hline 1 & 24 & 0.19 & 35 & 0.27 & 35 & 0.27 & 11 & 0.09 & 35 & 0.27 \\
\hline 2 & 14 & 0.11 & 11 & 0.09 & 16 & 0.13 & 16 & 0.13 & 85 & 0.66 \\
\hline 3 & 25 & 0.20 & 31 & 0.24 & 21 & 0.16 & 15 & 0.12 & 49 & 0.38 \\
\hline 4 & 36 & 0.28 & 33 & 0.26 & 27 & 0.21 & 17 & 0.13 & 27 & 0.21 \\
\hline 5 & 61 & 0.48 & 33 & 0.26 & 22 & 0.17 & 11 & 0.09 & 15 & 0.12 \\
\hline 6 & 67 & 0.52 & 46 & 0.36 & 18 & 0.14 & 4 & 0.03 & 20 & 0.16 \\
\hline 7 & 10 & 0.08 & 15 & 0.12 & 21 & 0.16 & 29 & 0.23 & 66 & 0.52 \\
\hline 8 & 29 & 0.23 & 39 & 0.30 & 33 & 0.26 & 13 & 0.10 & 27 & 0.21 \\
\hline 9 & 18 & 0.14 & 34 & 0.27 & 20 & 0.16 & 31 & 0.24 & 41 & 0.32 \\
\hline 10 & 8 & 0.06 & 19 & 0.15 & 9 & 0.07 & 28 & 0.22 & 82 & 0.64 \\
\hline 11 & 24 & 0.19 & 33 & 0.26 & 30 & 0.23 & 25 & 0.20 & 41 & 0.32 \\
\hline 12 & 11 & 0.09 & 23 & 0.18 & 32 & 0.25 & 37 & 0.29 & 31 & 0.24 \\
\hline 13 & 21 & 0.16 & 21 & 0.16 & 48 & 0.38 & 23 & 0.18 & 19 & 0.15 \\
\hline 14 & 38 & 0.30 & 51 & 0.40 & 43 & 0.34 & 6 & 0.05 & 4 & 0.03 \\
\hline 15 & 20 & 0.16 & 22 & 0.17 & 25 & 0.20 & 32 & 0.25 & 39 & 0.30 \\
\hline 16 & 39 & 0.30 & 64 & 0.50 & 24 & 0.19 & 6 & 0.05 & 15 & 0.12 \\
\hline
\end{tabular}




\begin{tabular}{|l|l|l|l|l|l|l|l|l|l|l|}
17 & 30 & 0.23 & 44 & 0.34 & 24 & 0.19 & 12 & 0.09 & 12 & 0.09 \\
\hline 18 & 50 & 0.39 & 55 & 0.43 & 50 & 0.39 & 11 & 0.09 & 2 & 0.02 \\
\hline 19 & 20 & 0.16 & 49 & 0.38 & 26 & 0.20 & 20 & 0.16 & 6 & 0.05 \\
\hline 20 & 20 & 0.16 & 42 & 0.33 & 44 & 0.34 & 9 & 0.07 & 7 & 0.05 \\
\hline 21 & 14 & 0.11 & 20 & 0.16 & 58 & 0.45 & 26 & 0.20 & 26 & 0.20 \\
\hline 22 & 14 & 0.11 & 18 & 0.14 & 44 & 0.34 & 30 & 0.23 & 29 & 0.23 \\
\hline 23 & 13 & 0.10 & 39 & 0.30 & 48 & 0.38 & 21 & 0.16 & 32 & 0.25 \\
\hline 24 & 13 & 0.10 & 33 & 0.26 & 36 & 0.28 & 22 & 0.17 & 18 & 0.14 \\
\hline 25 & 20 & 0.16 & 38 & 0.30 & 48 & 0.38 & 7 & 0.05 & 1 & 0.01 \\
\hline 26 & 8 & 0.06 & 34 & 0.27 & 41 & 0.32 & 37 & 0.29 & 22 & 0.17 \\
\hline
\end{tabular}

Table (4) Sorthing of answers of the questions of Kirkuk university Higher Educ.

\begin{tabular}{|c|c|c|c|c|c|c|c|c|c|c|}
\hline \multirow{3}{*}{ No } & \multicolumn{10}{|c|}{ Kirkuk university } \\
\hline & \multicolumn{2}{|c|}{ 1- More } & \multicolumn{2}{|c|}{ 2- Medium } & \multicolumn{2}{|c|}{ 3-Little } & \multicolumn{2}{|c|}{ 4-Zero/ nothing } & \multicolumn{2}{|c|}{ 5- Not avia-lable } \\
\hline & No & $\%$ & No & $\%$ & No & $\%$ & No & $\%$ & No & $\%$ \\
\hline 1 & 7 & 0.54 & 10 & 0.77 & 8 & 0.62 & 0 & 0.00 & 8 & 0.62 \\
\hline 2 & 4 & 0.31 & 0 & 0.00 & 10 & 0.77 & 4 & 0.31 & 14 & 1.08 \\
\hline 3 & 16 & 1.23 & 5 & 0.38 & 4 & 0.31 & 8 & 0.62 & 2 & 0.15 \\
\hline 4 & 18 & 1.38 & 8 & 0.62 & 4 & 0.31 & 2 & 0.15 & 2 & 0.15 \\
\hline 5 & 18 & 1.38 & 10 & 0.77 & 2 & 0.15 & 2 & 0.15 & 4 & 0.31 \\
\hline 6 & 18 & 1.38 & 14 & 1.08 & 0 & 0.00 & 2 & 0.15 & 2 & 0.15 \\
\hline 7 & 4 & 0.31 & 4 & 0.31 & 7 & 0.54 & 8 & 0.62 & 14 & 1.08 \\
\hline 8 & 6 & 0.46 & 8 & 0.62 & 8 & 0.62 & 5 & 0.38 & 10 & 0.77 \\
\hline 9 & 0 & 0.00 & 8 & 0.62 & 4 & 0.31 & 8 & 0.62 & 13 & 1.00 \\
\hline 10 & 0 & 0.00 & 22 & 1.69 & 6 & 0.46 & 10 & 0.77 & 16 & 1.23 \\
\hline 11 & 9 & 0.69 & 6 & 0.46 & 6 & 0.46 & 6 & 0.46 & 8 & 0.62 \\
\hline 12 & 0 & 0.00 & 7 & 0.54 & 6 & 0.46 & 18 & 1.38 & 4 & 0.31 \\
\hline 13 & 6 & 0.46 & 2 & 0.15 & 7 & 0.54 & 16 & 1.23 & 2 & 0.15 \\
\hline 14 & 12 & 0.92 & 6 & 0.46 & 14 & 1.08 & 1 & 0.08 & 0 & 0.00 \\
\hline 15 & 0 & 0.00 & 8 & 0.62 & 4 & 0.31 & 19 & 1.46 & 6 & 0.46 \\
\hline 16 & 14 & 1.08 & 12 & 0.92 & 8 & 0.62 & 0 & 0.00 & 0 & 0.00 \\
\hline 17 & 6 & 0.46 & 12 & 0.92 & 14 & 1.08 & 2 & 0.15 & 0 & 0.00 \\
\hline 18 & 5 & 0.38 & 12 & 0.92 & 12 & 0.92 & 4 & 0.31 & 0 & 0.00 \\
\hline 19 & 6 & 0.46 & 15 & 1.15 & 9 & 0.69 & 1 & 0.08 & 0 & 0.00 \\
\hline 20 & 8 & 0.62 & 10 & 0.77 & 12 & 0.92 & 2 & 0.15 & 6 & 0.46 \\
\hline 21 & 2 & 0.15 & 4 & 0.31 & 8 & 0.62 & 10 & 0.77 & 10 & 0.77 \\
\hline 22 & 0 & 0.00 & 9 & 0.69 & 8 & 0.62 & 8 & 0.62 & 10 & 0.77 \\
\hline 23 & 0 & 0.00 & 4 & 0.31 & 11 & 0.85 & 9 & 0.69 & 12 & 0.92 \\
\hline 24 & 2 & 0.15 & 10 & 0.77 & 14 & 1.08 & 6 & 0.46 & 3 & 0.23 \\
\hline 25 & 2 & 0.15 & 24 & 1.85 & 8 & 0.62 & 0 & 0.00 & 0 & 0.00 \\
\hline
\end{tabular}


8

0.62

18

1.38

6

0.46

Table (5) Sorthing of answers of the questions of the three universities.

\begin{tabular}{|c|c|c|c|c|c|c|c|c|c|c|}
\hline \multirow{3}{*}{ No } & \multicolumn{10}{|c|}{ Sum of all percentages } \\
\hline & \multicolumn{2}{|c|}{ 1- More } & \multicolumn{2}{|c|}{ 2- Medium } & \multicolumn{2}{|c|}{ 3- Little } & \multicolumn{2}{|c|}{ 4-Zero/ nothing } & \multicolumn{2}{|c|}{ 5- Not avia-lable } \\
\hline & No & $\%$ & No & $\%$ & No & $\%$ & No & $\%$ & No & $\%$ \\
\hline 1 & & 0.90 & & 1.34 & & 1.12 & & 0.21 & & 1.06 \\
\hline 2 & & 0.56 & & 0.34 & & 1.06 & & 0.55 & & 2.06 \\
\hline 3 & & 1.57 & & 0.90 & & 0.74 & & 0.82 & & 0.76 \\
\hline 4 & & 1.88 & & 1.15 & & 0.79 & & 0.40 & & 0.50 \\
\hline 5 & & 2.13 & & 1.34 & & 0.51 & & 0.35 & & 0.55 \\
\hline 6 & & 2.21 & & 1.61 & & 0.40 & & 0.30 & & 0.46 \\
\hline 7 & & 0.45 & & 0.54 & & 0.85 & & 1.09 & & 1.98 \\
\hline 8 & & 0.97 & & 1.13 & & 1.06 & & 0.60 & & 1.19 \\
\hline 9 & & 0.26 & & 1.12 & & 0.63 & & 1.10 & & 1.56 \\
\hline 10 & & 0.13 & & 2.01 & & 0.72 & & 1.23 & & 2.25 \\
\hline 11 & & 1.00 & & 0.94 & & 0.93 & & 0.90 & & 1.12 \\
\hline 12 & & 0.18 & & 0.91 & & 0.98 & & 1.87 & & 0.81 \\
\hline 13 & & 0.76 & & 0.56 & & 1.25 & & 1.56 & & 0.45 \\
\hline 14 & & 1.36 & & 1.22 & & 1.70 & & 0.24 & & 0.11 \\
\hline 15 & & 0.26 & & 0.90 & & 0.79 & & 1.97 & & 1.00 \\
\hline 16 & & 1.55 & & 1.74 & & 1.10 & & 0.19 & & 0.19 \\
\hline 17 & & 0.88 & & 1.53 & & 1.61 & & 0.31 & & 0.24 \\
\hline 18 & & 1.07 & & 1.61 & & 1.55 & & 0.49 & & 0.13 \\
\hline 19 & & 0.77 & & 1.80 & & 1.24 & & 0.38 & & 0.14 \\
\hline 20 & & 0.94 & & 1.42 & & 1.57 & & 0.37 & & 0.59 \\
\hline 21 & & 0.43 & & 0.69 & & 1.44 & & 1.12 & & 1.06 \\
\hline 22 & & 0.30 & & 1.05 & & 1.24 & & 1.06 & & 1.10 \\
\hline 23 & & 0.27 & & 0.99 & & 1.45 & & 0.98 & & 1.28 \\
\hline 24 & & 0.40 & & 1.35 & & 1.64 & & 0.78 & & 0.48 \\
\hline 25 & & 0.51 & & 2.50 & & 1.25 & & 0.16 & & 0.09 \\
\hline 26 & & 0.15 & & 0.75 & & 1.09 & & 1.95 & & 0.78 \\
\hline
\end{tabular}

